\title{
Civilización, barbarie e historia (sobre El miedo a los bárbaros de Tzvetan Todorov)
}

\author{
Civilization, Barbarism and History \\ (on Tzvetan Todorov's La Peur des Barbares)
}

JESÚS NAVARRO REYES*

Resumen: Nota crítica a propósito de TODOROV, Tzvetan: El miedo a los bárbaros: más allá del choque de civilizaciones, Noemí Sobregués (tr.), Galaxia Gutenberg/Círculo de Lectores, Barcelona, 2008, 312 p.

Palabras clave: choque de civilizaciones, tolerancia, fanatismo, identidades culturales, memoria histórica.

\begin{abstract}
Critical note on TODOROV, Tzvetan: El miedo a los bárbaros: más allá del choque de civilizaciones, Noemí Sobregués (tr.), Galaxia Gutenberg/Círculo de Lectores, Barcelona, 2008, $312 \mathrm{p}$.
\end{abstract}

Keywords: clash of civilizations, tolerance, fanatism, cultural identities, historical memory.

El miedo a los bárbaros es un libro de reacción, una réplica sagaz, pertinente y necesaria a otra obra que ha despertado tantas adhesiones como rechazos desde que fuera publicada a mediados de los años 90: El choque de civilizaciones, de Samuel P. Huntington. ${ }^{1}$ La obra de Huntington resultó para algunos desconcertantemente acertada, profética incluso: un lustro antes de los atentados del 11 de septiembre, que habrían de forzar a muchos a cambiar su concepción de las relaciones internacionales e interculturales, Huntington ya vaticinaba que, tras el fin de la guerra fría, los conflictos que marcarían los comienzos del siglo XXI serían de carácter civilizatorio, con un claro protagonismo de las diferencias religiosas. Algunos creen que este paradigma ayuda a comprender el nuevo auge de la yihad y la escalada de tensión y de violencia a la que pudimos asistir durante la 'era Bush', que habrían tenido como causa subyacente este choque de civilizaciones irreconciliables. La obra de Todorov

Fecha de recepción: 05/06/2012. Fecha de aceptación: 15/03/2013.

* Profesor titular del área de filosofía en la Universidad de Sevilla (jnr@us.es, personal.us.es/jnr), Navarro Reyes ha trabajado sobre la influencia de Montaigne en el modelo moderno de subjetividad, y está interesado en cuestiones de pragmática, filosofía de la mente y teoría de la acción. Recientemente ha publicado «Autonomía, tolerancia y civilización» (Revista Internacional de Pensamiento Político, 6, 33-51) y Cómo hacer filosofía con palabras: a propósito del desencuentro entre Searle y Derrida (Fondo de Cultura Económica, Madrid, 2010).

1 El choque de civilizaciones y la reconfiguración del orden mundial, Paidós, Barcelona, 2006 (publicación original de 1996). 
se entiende mejor en el momento en que el lector se percata de que - a pesar de que escasean las referencias explícitas a la obra de Huntington-toda ella es un rechazo global y sistemático de esta idea: un esfuerzo por refutarla con la ayuda de los hechos y ofrecer un paradigma alternativo ${ }^{2}$.

El libro comienza planteando su tesis fundamental: que el miedo a los bárbaros es lo que nos hace bárbaros. El interés de la frase reside en el doble sentido de la palabra «bárbaros»: en su primera aparición se refiere a los otros, los que son distintos de nosotros, aquellos que proceden de una cultura y una tradición diferentes, cuyas costumbres nos parecen inaceptables, 'incivilizadas' o incluso inhumanas; en su segunda aparición, en cambio, somos nosotros los que nos hacemos bárbaros, según una expresión que ya no se refiere a los otros, sino a nosotros mismos: a lo que lamentablemente podemos llegar a ser; o, más bien, a lo que nunca hemos dejado de ser. Es precisamente al temer la sinrazón de los otros cuando nos hacemos otros para nosotros mismos, y acabamos convirtiéndonos en aquellos bárbaros que tanto temíamos.

Al igual que «bárbaro» o «barbarie», también el término «civilización» tiene un doble sentido ${ }^{3}$. Por una parte, tiene un significado desprovisto de valoración, que más bien describe los rasgos idiosincráticos de un determinado pueblo. Un segundo sentido es, en cambio, axiológico: señala un valor que corresponde a las acciones o actitudes de los seres humanos, una constante o un ideal común a las distintas culturas o civilizaciones. Creer que lo civilizado se encuentra única o prioritariamente en una determinada civilización, o que sólo una civilización, la nuestra, es propiamente civilizada, es confundir ambas ideas. El núcleo de la idea de lo civilizado es, según Todorov, la inclusión del otro: la aceptación de que, a pesar de su diferencia, no quede expulsado del ámbito de lo humano. Y esta idea, en su opinión, pertenece por igual a todas las culturas o civilizaciones. Es en el ámbito europeo donde $l o$ civilizado ha recibido un mayor desarrollo desde un punto de vista legislativo y social, como herencia de la Ilustración, pero eso no nos convierte en sus únicos representantes, ni nos libra del riesgo de caer en su opuesto: la barbarie.

El planteamiento de Huntington, por el contrario, se construía sobre la noción de civilización como sinónimo de cultura, y sólo parecía admitir una articulación de los valores morales en el seno de cada cultura o civilización, con el respaldo de un credo religioso. Este enfoque abocaba al enfrentamiento, sobre todo desde el momento en que se consideraba que la beligerancia y la tensión son constitutivas de todo contexto internacional. Ante la caída de la Unión Soviética, Huntington no podía dejar de preguntarse quién ocupará en el futuro su lugar, dando por sentado que la identidad occidental, y en concreto la norteamericana,

2 El rechazo a las tesis de Huntington ha sido bastante generalizado en los últimos años. Destacan las críticas de A. Remiro Brotóns (Civilizados, bárbaros y salvajes en el nuevo orden internacional, McGraw-Hill, Madrid, 1996), G. Corm (La fractura imaginaria. Las falsas raíces del enfrentamiento entre Oriente y Occidente, Tusquets, Barcelona, 2004), F. Halliday (El Islam y el mito del enfrentamiento, Bellaterra, Barcelona, 2005), A. Sen (Identidad y violencia. La ilusión del destino, Katz, Buenos Aires, 2007) o Amin Maalouf (El desajuste del mundo. Cuando nuestras civilizaciones se agotan, Madrid, Alianza, 2009, pp. 271 y passim). También ha tenido sus defensores, generalmente de una tendencia marcadamente conservadora, como T. Blankley (The West's Last Chance: Will We Win the Clash of Civilizations?, Regnery, Washington, 2005).

3 Acerca del concepto de civilización y su aplicación a las relaciones internacionales actuales, cfr. J.M. Pérez Rodríguez: «Balance y perspectivas de la Alianza», Revista Internacional de Pensamiento Político, 6, 2011, pp. 64-76. 
no puede persistir sin un enemigo que esté a su altura. ¿Quiénes serán nuestros próximos bárbaros?, es lo que Huntington intentaba averiguar en su concienzudo estudio. ¿Cómo evitar que nosotros mismos nos convirtamos en bárbaros?, es la pregunta alternativa que decide formularse Todorov.

El libro consta de cinco capítulos. El primero de ellos, «Barbarie y civilización», analiza la génesis histórica de esos términos, intentando reordenar los conceptos que utilizará en el resto del libro de manera que permitan la emergencia de una perspectiva alternativa. El segundo estudia la formación de «Identidades colectivas» en el seno de los estados modernos, señalando que todo ser humano está constituido por un entramado de identidades múltiples, cuya simplificación, siguiendo a Amartya Sen, conduce hacia la exclusión y la violencia. El capítulo tercero, «La guerra de los mundos», denuncia los nocivos efectos del planteamiento maniqueo y simplista que describe la situación actual como confrontación entre una sociedad civilizada, la occidental, y otra incivilizada y bárbara, la islámica, prestando especial atención a la cuestión de la tortura. El capítulo cuarto, «Navegar entre escollos», constituye un análisis sutil y perspicaz de distintos episodios recientes donde la cultura occidental ha dado muestras de intolerancia y xenofobia, provocando innecesariamente, y en ocasiones de manera burda e irrespetuosa, a los ciudadanos de las culturas islámicas (desde la política cultural de Amsterdam hasta las caricaturas danesas de Mahoma o el tristemente famoso discurso de Benedicto XVI en Ratisbona). Finalmente, el capítulo quinto defiende una idea de «identidad europea» como estrategia de convivencia y unidad entre naciones, más que como unidad nacional basada en rasgos culturales compartidos; una idea que, aun corriendo el riesgo de diluirse en la universalidad, tiene como misión en el contexto internacional ofrecer un modelo exitoso de convivencia tolerante (a pesar de que somos ya bien conscientes de los propios déficits democráticos de este modelo ${ }^{4}$ ).

Creo que la obra de Todorov es oportuna y acertada. Un esfuerzo encomiable por reconsiderar los conceptos y las ideas con las que nos enfrentamos a nuestro convulso presente histórico desde una perspectiva decididamente ilustrada, que intenta aunar la pluralidad cultural con la defensa universal de principios comunes a todas las culturas. Todorov sabe articular las objeciones de sentido común que la mayor parte de la población sostendría probablemente ante la proliferación de ciertos extremismos en las sociedades occidentales y en algunos de sus más importantes gobiernos, que parecen en ocasiones sucumbir a la xenofobia y el enfrentamiento esencialista entre tradiciones y culturas. El búlgaro hace todo lo posible por dinamitar ese esencialismo con la fuerza de los hechos que, en su opinión, demuestran que «no son las identidades en sí mismas las que causan los conflictos, sino que son los conflictos los que convierten en peligrosas las identidades» (p. 139). Las diferencias religiosas, por ejemplo, no suelen ser las detonantes de la violencia, sostiene Todorov, sino más bien una excusa que responde a motivaciones menos confesables. El origen de la violencia no está por tanto en el choque entre culturas, sino más bien en la desculturización, en la pérdida del marco esencial donde se construye la vida en común.

4 Cfr. a este respecto las aportaciones de H. Kaelble (Caminos hacia la democracia. Los déficits democráticos de la Unión Europea, Biblioteca Nueva, Madrid, 2005), Follesdal, A. \& Hix S. («Why There is a Democratic Deficit in the EU», Journal of Common Marquets Studies, 44:3, 2006, pp. 533-562) o el volumen colectivo La constitución destituyente de Europa: razones para otro debate constitucional (Chaves Giraldo, P. et al (eds.), Madrid, Catarata, 2005). 
Quizás la principal objeción que pueda plantearse a Todorov en este sentido es que no parece que sea fácil construir dicho marco de manera que su defensa y promulgación universal no sea interpretada como imposición de una cultura específica, la occidental, sobre el resto, evitando así que la llegada de la modernidad, por decirlo con palabras de Amin Maalouf, sea asumida por otras civilizaciones como una imposición «que viene del mundo del otro» ${ }^{5}$. Si realmente aspiramos a construir un marco común de convivencia, es preciso aceptar que todas las culturas van a tener que ceder en terrenos donde en principio no parecen estar muy dispuestas a la negociación, incluida nuestra cultura occidental, que se encuentra ante la tesitura de retroceder en lo que generalmente se considera victorias históricas, como la libertad de expresión o de prensa, o la laicidad de la educación y del estado 6 .

Pero no quisiera acabar sin apuntar un aspecto que, a la vista de algunas opiniones defendidas posteriormente por Todorov, parece entrañar cierto peligro. Defendiendo una visión compleja y realista de la historia, Todorov sostiene en este libro que es preciso huir del victimismo histórico de ciertos grupos sociales que construyen su propia identidad sobre visiones maniqueas del pasado, en las que se demoniza a los responsables de represiones o violencias colectivas sin intentar comprender la complejidad del momento histórico en que éstas tuvieron lugar (pp. 90-95). Éstas son, en opinión de Todorov, interpretaciones tendenciosas de los hechos respaldadas por el deseo de «obtener el estatus de antigua víctima de violencias colectivas, un estatus que se transmite de generación en generación» y que habría de garantizar ciertos derechos o privilegios en el presente. No le falta cierta razón a Todorov al sostener que a este discurso victimista se está otorgando hoy la función que en épocas pasadas correspondió al relato heroico de los vencedores, ya completamente desprestigiado. El problema llega cuando, en beneficio de una lectura menos maniquea, Todorov aboga por lo que denomina «la historia real»:

«Si elegimos del pasado únicamente lo que conviene al presente, nos libramos a una lectura muy selectiva y traicionamos la historia real, que sustituimos por una historia piadosa que se adapta a las exigencias de lo 'políticamente correcto' de nuestra época» (p. 248, el subrayado es mío).

Resulta difícil sostener hoy la apelación a esa «historia real» sin ser bien consciente de que toda historia implica una selección, una ordenación narrativa y una articulación de causas y efectos, que nunca es ni puede ser completamente neutra. En concreto, es inevitable que esa articulación incorpore una consideración, por parte del historiador, de ciertas situaciones 'contrafácticas' que nunca tuvieron lugar, pero que podrían haber acontecido y, en su mera posibilidad, dotan de sentido al discurrir del pasado. Porque, si la historia aspira a tener sentido, no puede consistir sólo en la narración de lo efectivamente sucedido, ni en la mera enumeración de lo que tuvo lugar? . Es en ese punto donde siempre cabe cierta

5 Identidades asesinas, Madrid, Alianza, 2008, pp. 55-92.

6 He desarrollado esta crítica con más detalle en «Autonomía, Tolerancia y Civilización», Revista Internacional de Pensamiento Político, 6, 2011, pp. 33-51.

7 En otros lugares de su obra, el propio Todorov parece más sensible a las necesidades de una historia «interpretativa» que vaya más allá de la acumulación de verdades fácticas (cfr. por ejemplo La experiencia totalitaria, Madrid, Galaxia Gutenberg/Círculo de Lectores, 2010, p. 254). Un buen modo de acercarse al amplísimo 
arbitrariedad, una posicionamiento voluntario, que ha de responder a intereses y objetivos propios del presente del historiador, más que de la época estudiada. Intereses que, de no ser tomados expresamente en consideración, se apoderan de la actividad del historiador de manera impremeditada y peligrosa.

Ese es, creo, el caso de un artículo posterior de Todorov ${ }^{8}$, donde cuestiona el discurso victimista de los reprimidos por la dictadura de Argentina de los años setenta y ochenta. ${ }^{9}$ En dicho artículo, Todorov sostiene que el momento histórico en el que dicha dictadura tuvo lugar, ante el auge de distintos terrorismos de izquierdas y revoluciones comunistas de consecuencias devastadoras, hace que la crítica al «terrorismo de estado» de aquél momento haya de ser matizada, pues la mayoría de los reprimidos «luchaban en nombre de una ideología que, si hubiera salido victoriosa, probablemente habría provocado tantas víctimas, si no más, como sus enemigos». Aquí entran en juego aquellos contrafácticos a los que me refería antes: en el momento en que Todorov no está constatando los hechos desnudos, levantando acta objetiva de lo acaecido en 'la historia real', sino que pasa a imaginar mundos posibles, jamás efectivamente acontecidos, donde decisiones distintas habrían conducido por otros derroteros. En esos momentos resulta difícil saber si Todorov está sólo intentando comprender lo ocurrido, o si por el contrario hay incluso cierta intención de justificarlo, pues sus palabras llegan a constituir una defensa de las mismas excusas que condujeron en su momento hasta aquellos actos de lesa humanidad, un paliativo para lo injustificable o, cuando menos, una matización del carácter nocivo de aquellos actos deleznables, ante la vista los potenciales efectos perniciosos que podría haber tenido una actitud menos decidida en beneficio del orden público ${ }^{10}$. Un artículo en mi opinión lamentable, que empaña los logros de este libro precedente, cuyas impecables intenciones, como puede comprobarse, corren el riesgo de extraviarse. Cuán profundamente está arraigada esta posibilidad del extravío en la concepción ilustrada de la historia que sostiene Todorov es una cuestión difícil de valorar, pero que no conviene pasar por alto ${ }^{11}$.

debate contemporáneo sobre la objetividad de la historia es el capítulo de Julián Casanova «Los límites de la objetividad y el desafío posmodernista», en Forcadell Álvarez, Carlos (ed.): Razones de historiador. Magisterio y presencia de J.J. Carreras, Zaragoza, Institución 'Fernando el Católico', 2009, pp. 321-334.

8 «Un viaje a Argentina», El País, 07/12/2010.

9 Sin referencias a la dictadura argentina, Todorov ya había esbozado una crítica similar de los privilegios reivindicados por discursos victimistas en Los abusos de la memoria, Barcelona, Paidós, 2000, pp. 53ss, donde denunciaba que «Si se consigue establecer de manera convincente que un grupo fue víctima de la injusticia en el pasado, esto le abre en el presente una línea de crédito inagotable. [...] En vez de tener que luchar para obtener un privilegio, éste es recibido de oficio por la sola pertenencia al grupo antes desfavorecido» (pp. 54-6).

10 Arriesgando un argumento ad hominem, podría explicarse este desafortunado juicio de Todorov como una respuesta visceral ante la posibilidad histórica de que en Argentina hubiera tenido lugar un régimen totalitario comunista similar al que el propio escritor sufrió en la Bulgaria de su juventud. Cfr. al respecto La experiencia totalitaria, op cit, pp. 9-47.

11 Esta publicación ha contado con ayuda del proyecto de investigación «Agencia, normatividad y racionalidad: la presencia del sujeto en la acción» (FFI2011-25131, Ministerio de Investigación e Innovación, 2012-2015). Agradezco los comentarios de los evaluadores de Daímon, que me han aportado referencias bibliográficas muy pertinentes. 